\title{
MICRO ECONOMISCHE MODELLEN VOOR HET MARKETING BELEID
}

door Prof. Dr. G. J. Aeyelts Averink $\dagger$

\section{Inleiding}

Bij menige onderneming valt een discrepantie waar te nemen tussen de betrekkelijk strakke beleidslijnen voor het produktiebeleid en de meer intuitieve en gedesintegreerde wijze waarop het commerciële beleid is geformuleerd en wordt gevoerd. Dit onderscheid komt niet zo zeer voort uit een verschil qua behoefte aan een objektieve en systematische aanpak van problemen, of uit een mentaliteitsverschil tussen de betrokken ondernemingsfunktionarissen, als wel uit de aard van de problemen zelf, en vooral de moeite die het kost deze problemen tot een bevredigende oplossing te brengen. Op het commerciële vlak - en wij beperken ons daarbij gemakshalve tot het verkoopbeleid - zijn vergelijkenderwijs minder zekerheden, minder constanten, minder gegevens in de oorspronkelijke betekenis van ,,bekenden", dan in de sfeer van de produktie- en waarschijnlijk ook de overige ondernemingsfunkties. Die onzekerheid geldt het meest voor al datgene wat zich buiten de onderneming om op de markt voltrekt, maar eveneens voor de doelmatigheid van het eigen commerciële programma, ex ante en dikwijls ook ex post. Bewust chargerend vanuit het standpunt van een marktonderzoeker, zou men kunnen stellen, dat de commerciële leiding wordt gedwongen tot handelen vanuit ervaring en intuitie bij gebrek aan inzicht en voldoende informatie omtrent de struktuur en ontwikkeling van de markt en de eigen positie van de onderneming op die markt.

De gewraakte onzekerheid behoeft niet te gelden voor de vaststelling van de doeleinden van het verkoopbeleid of de benoeming van de verkooppolitieke middelen die kunnen worden ingezet. De doeleinden van het verkoopbeleid zijn te beschouwen als afgeleiden van de doelstellingen van de onderneming als geheel, en kunnen vrijwel steeds worden geformuleerd in termen van verkoopvolume, bruto-opbrengsten en/of winstbijdragen, nader gespecificeerd naar tijd en markt.

Het is mogelijk, in navolging van Tinbergen, een onderscheid te maken tussen vaste en flexibele doeleinden van het beleid. Vaste doeleinden impliceren dat een bepaald niveau van de doelvariabele wordt nagestreefd, terwijl bij flexibele doeleinden een kritisch gebied of interval voor de doelvariabele wordt aangeduid, waarvan de grens of de grenzen niet mag/mogen worden overschreden. Als speciaal geval van een flexibele doelstelling wordt beschouwd een doelstelling welke het maximeren of minimeren van een doelvariabele inhoudt. Wil er niet een strijdigheid tussen de doeleinden onderling ontstaan, dan heeft men zich in dit opzicht te beperken tot slechts één doelvariabele, waarvoor een zo extreem mogelijke waarde wordt nagestreefd. Een aanvaardbare kombinatie van doeleinden is dus b.v. de volgende:

- maximeer de bruto-opbrengsten

- verkoopvolume tussen de grenzen X en $\mathrm{Y}$

- netto-winst bijdrage tenminste $Z$ 
Waar de tweede en derde doelstelling in dit voorbeeld tezelfdertijd met de eerste dienen te worden gerealiseerd, kan slechts een voorwaardelijke maximering van de bruto-opbrengsten plaatsvinden. De hoofddoelstelling wordt hier beperkt door twee (eveneens flexibele) nevendoeleinden, welke ook mogen worden gezien als randvoorwaarden.

Andere randvoorwaarden kunnen voortvloeien uit het gebruik van de nader te behandelen middelen (instrumenten) van het verkoopbeleid, zoals een kritisch interval t.a.v. de verkoopprijs, een bovengrens aan de uitgaven voor verkoopbevordering (liquiditeitsvoorwaarde), e.d., ofwel samenhangen met de ondernemingsdoeleinden op zeer lange termijn, zoals het handhaven van het marktaandeel, het bereiken van een zekere spreiding der opbrengsten over deelmarkten of produkten, etc. Zoals hieruit blijkt kan - zeker wat betreft de planning op korte termijn - een complex van doeleinden vereist zijn, welke deels in absolute termen, deels in relatieve termen gegoten zijn. Aan dit complex kan de eis worden opgelegd dat het consistent is, doelmatig (relevant voor de verkoopfunktie en de onderneming als geheel, en niet-overlappend) en voorts ook ",haalbaar" (,feasible”) met het oog op de middelen die ter beschikking staan.

Ongeacht de vraag of commerciële afdelingen in de praktijk voorwaardelijke maxima of minima als doelstellingen wensen te hanteren, is het niettemin duidelijk dat een dergelijk complex van doeleinden en randvoorwaarden in harmonie kan zijn met de eenduidige theoretische economische doelstelling van winstmaximering van de onderneming op lange termijn. Die harmonie zal gelukkig ook aanwezig kunnen worden geacht t.a.v. alternatieve ondernemingsdoeleinden, waarbij maximering van de winst niet voorop staat.

\section{De Marketing Mix}

Richten we de aandacht nu op de middelen van het verkoopbeleid, welke tezamen gewoonlijk worden aangeduid als de ,marketing mix", dan kan een zinvol onderscheid worden gemaakt tussen kwalitatieve en kwantitatieve instrumenten van de verkooppolitiek. Daarnaast valt een tweedeling te maken naar instrumenten welke deel uitmaken van de marktofferte door de onderneming, en anderzijds instrumenten die de bewerking van de markt regarderen. Aldus ontstaat het volgende beeld:

Instrumenten gerelateerd aan de

\begin{tabular}{lll}
\hline & MARKTOFFERTE & MARKTBEWERKING \\
\hline Kwalitatief & $\begin{array}{l}\text { produkteigenschappen } \\
\text { krijs en rabatten }\end{array}$ & $\begin{array}{l}\text { distributiekanalen } \\
\text { reklame en vertegenwoordiger }\end{array}$ \\
\hline
\end{tabular}

De vier cellen van dit schema worden gewoonlijk verbonden met de vier P's van MCCARTHY: produkt, prijs, promotie en punt van verkoop. De indeling hierboven voegt hieraan iets toe, $\mathrm{nl}$. dat bepaalde instrumenten vragen om keuzebeslissingen (de kwalitatieve) en andere om intensiteitsbeslissingen (de kwantitatieve). Instrumenten welke de marktofferte raken refereren aan elke eenheid welke ten verkoop wordt aangeboden, de marktbewerkingsinstru- 
menten daarentegen aan groepen van direkte of uiteindelijke afnemers. Dit is van belang indien verschillende geografische markten met elkaar worden vergeleken, omdat prijs en kwaliteit dezelfde kunnen zijn voor cen vergelijkbaar effekt op de markt, terwijl distributie en promotie door omvang en struktuur van de markt geconditioneerd zijn.

Zoals hierboven beschreven betreft de marketing mix kennelijk één afzonderlijk produkt en de daarvoor op te stellen marktofferte. Evenwel zal vrijwel steeds sprake zijn van een assortiment van produkten, zodat de assortimentskeuze eveneens als een instrument van het commerciële beleid dient te worden opgevat. Op dit punt kan men van mening (of smaak) verschillen: naar believen kan de marketing mix worden uitgebreid tot deze alle produkten, merken en markten omvat, of wel zij wordt beperkt tot specifieke markt-merk-produkt kombinaties. De keuze hieruit zal veelal op praktische gronden dienen te geschieden, nl. voorzover van een gedifferentieerd commercieel beleid sprake is en dit zijn weerslag vindt in de organisatie van de verkoopfunktie. Op deze wijze ontstaat dan het beeld van een conglomeraat van marketing mixes van verschillende ordes, die tezamen het gehele commerciële instrumentarium omvatten.

Een minder aangenaam gevolg van een dergelijke opzet kan zijn, dat de onderscheiden marketing mixes niet refereren aan onderling onafhankelijke offertes en markten, terwijl instrumenten van ,hogere orde" veelal ondeelbaar zijn in die zin, dat zij niet kunnen worden toegerekend aan instrumenten van ,lagere orde". Voorbeelden van dergelijke komplikaties zijn ,merknaam"-reklame welke alle produkten onder dit merk in feite raakt, de keuze van distributiekanalen voor verscheidene produkten tegelijk, de substitutie tussen de variëteiten van eenzelfde produkt, komplementariteit tussen verschillende produkten, etc.

Eenvoudigheidshalve zullen wij ons in het volgende beperken tot de meest elementaire casus van één markt, één produkt en één merk, en dus ook één marketing mix.

\section{Relatie tussen doeleinden en middelen}

Met de aanduiding van doeleinden en middelen van het verkoopbeleid wordt duidelijk dat bij de opstelling van marketing plannen rekening moet worden gehouden met een groot aantal faktoren, die deels kwalitatief en deels kwantitatief van aard zijn. De vraag is nu welke samenhang tussen doeleinden en middelen moet worden onderkend.

Naar analogie van een welbekend begrip uit de leer van de produktie, valt in dit verband te denken aan een commerciële produktiefunktie, welke tot uitdrukking brengt met welke alternatieve kombinaties van produktiefaktoren (de marketing instrumenten) een vaste hoeveelheid van een bepaald produkt (de marketing doeleinden) kan worden voortgebracht.

Evenals in het geval van de ,klassieke” produktiefunktie mag worden verwacht voor de commerciële produktiefunktie, dat de produktiefaktoren slechts beperkt substitueerbaar zijn, en dat de invloed van verschillende faktoren tezamen meer is dan de som van de afzonderlijke invloeden, zoals bv. 
wordt gerealiseerd middels een multiplikatieve funktie. (Vgl. de CobbDouglas-funktie)

De gelijkenis is hiermee evenwel ten einde, want de bedoelde commerciële relatie kent geen vaste „technische” coëfficiënten. Het is juist de wisselvalligheid van deze coëfficiënten, welke de commerciële planning zoveel problematischer maakt dan planning in de sfeer van de fysieke produktie. Oorzaken van deze wisselvalligheid zijn o.m.:

- het feit dat de commerciële relatie geen technisch proces beschrijft maar een gedrag van een massa individuen, gezins- of bedrijfshuishoudingen. Dit gedrag is zelden stereotiep, en goeddeels situatie- en tijdsgebonden.

- de afstand tussen de onderneming als aanbieder en de uiteindelijke afnemer in het geval van marketing gericht op partikuliere konsumptie. Enerzijds leidt dit mogelijkerwijs tot vertraging van het effekt van commerciële aktiviteiten, anderzijds tot onvolledige of onjuiste overdracht van de informatie bedoeld om de afstand te overbruggen. Voorzover de zelfstandige handel als intermediair wordt ingeschakeld is de onderneming tevens afhankelijk van het gedrag van deze direkte afnemers.

- de aanwezigheid van mede-aanbieders op dezelfde markt, wier autonoom gedrag evenzeer pleegt te fluktueren, maar die bovendien een reaktie te zien geven op vele akties van de eigen onderneming.

De commerciële produktiefunktie is dus steeds een gedragsrelatie, waarin behalve het eigen gedrag de gedragingen van drie andere marktpartijen een rol spelen: de uiteindelijke afnemers, de ,,wederverkopers" en de konkurrerende aanbieders. Waar elk dezer derden een min of meer zelfstandig gedrag laat zien, dat voorts situatie- en tijdsgebonden is, kan moeilijk worden gesproken van een constante relatie tussen marketing doeleinden en middelen van de individuele aanbieder.

Een uitweg uit de impasse van voortdurende variabiliteit van de relatie in kwestie zou zijn om deze telkenmale experimenteel vast te stellen op verkleinde schaal. Voor deze "technische" oplossing ontbreekt het de onderneming echter meestal aan tijd, financiële of ook praktische mogelijkheden. Ongeacht het belang van tests en proefmarkten voor het commerciële beleid in detail (vgl. hiervoor b.v. Sevin en Banks), biedt deze methode geen realistisch antwoord op de vragen van de commerciële strategie in totaal. Dan blijft als enige mogelijkheid over om op basis van de opgedane ervaring met hetzelfde of zo nodig andere produkten en markten een meeromvattend beeld in de vorm van een model op te stellen dat de komplexiteit van het marktgedrag in de tijd althans bij benadering recht doet wedervaren. In dit model dienen behalve de beheersbare faktoren (instrumenten) ook de nietbeheersbare faktoren (gedrag van concurrenten, de omgeving, etc.) expliciet te worden opgenomen. Bij een voldoende gedetailleerde specifikatie van dit model mag men dan de hoop koesteren, dat het qua struktuur (en dus bepaalde coëfficiënten) een zekere stabiliteit in de tijd laat zien. Het is de taak van de marktonderzoekafdeling om primair vorm en inhoud aan dit model te geven.

Het voorgaande maakt duidelijk dat de hypothese van een commerciële produktiefunktie, welke een exclusieve relatie tussen marketing doeleinden 
en middelen poogt te leggen, in feite verworpen moet worden, omdat zij een bedriegelijke eenvoud suggereert. Het lijkt niet te veel gezegd, dat vele marktonderzoekers in deze ook gaarne de weg van de minste weerstand zoeken, en op basis van uitsluitend interne data een relatie trachten te schatten tussen b.v. verkoopcijfers enerzijds en de eigen prijs en reklameuitgaven anderzijds. Hoe hechter de gevonden samenhang des te groter het gevaar, dat de resultaten als betrouwbaar worden beschouwd en vervolgens misbruikt worden voor planning of controle doeleinden.

In plaats van een eenvoudige produktiefunktie dient dus te worden gezocht naar een systeem van relaties, waarbij de eigen inbreng van de onderneming wellicht slechts een bescheiden funktie vervult. Centraal in zo'n systeem zal staan wat de economist als de ,eigen" vraagfunktie van de onderneming betitelt: de afhankelijkheid van de eigen afzet (in volume) t.o.v. alle vraagbepalende faktoren, ongeacht hun beheersbaarheid. Tezamen met de winstdefinitie-vergelijking, de kostenrelaties en de eventuele randvoorwaarden vormt de eigen vraagfunktie dan een model, dat als integraal marketing model kan worden beschouwd.

\section{Het onderzoekprobleem}

De marktonderzoeker, aan wie wordt gevraagd een schatting te maken van de eigen vraagfunktie van de onderneming op basis van historisch cijfermateriaal, beschikt over een arsenaal van zeer krachtige, simultane schattingstechnieken en veelal ook over de steun van een elektronisch rekentuig, maar deze baten nauwelijks bij de eerste faze van zijn onderzoek, te weten de opzet van het model en de formulering van voorlopige hypothesen omtrent het verband tussen de eigen afzet en de vraagbepalende faktoren.

Zijn primaire probleem is om de indrukwekkend lange lijst van kandidaatfaktoren terug te brengen tot hanteerbare proporties. Hanteerbaarheid impliceert allereerst een proces van kwantificering, ook t.a.v. faktoren die in feite kwalitatief van karakter zijn. (Vgl. eerder.) Daarnaast zal een reduktie van het aantal faktoren noodzakelijk zijn, omdat het aantal beschikbare waarnemingen (zeg: de lengte van de tijdreeks) veelal aanzienlijk kleiner is dan het aantal kandidaatfaktoren, terwijl ten behoeve van een statistisch betrouwbaar resultaat juist naar een omgekeerde verhouding dient te worden gestreefd, in die zin, dat voldoende vrijheidsgraden voor de statistische schatting overblijven. Bij dit reduktieproces zal worden gestreefd naar opname van zoveel mogelijk onafhankelijke beinvloedingsfaktoren, die voorts ieder voor zich een statistisch ,signifikante" bijdrage aan de totale verklaring van de afzetvariaties hebben geleverd. Daarbij zullen een aantal faktoren, die theoretisch relevant genoemd mogen worden, moeten afvallen, omdat hierover geen betrouwbare informatie ter beschikking staat, of omdat deze in de onderzoekperiode weinig of geen variatie hebben laten zien. De aldus gereduceerde lijst zal dus een compromis tussen het wenselijke en het haalbare impliceren.

Voor een verdergaande reduktie zal de onderzoeker o.m. de volgende procedures kunnen aanwenden:

1 clustering, d.w.z. het samenvoegen van faktoren tot één samengestelde, 
totaal faktor. Zo zal het dikwijls mogelijk zijn de marketing mixes door een 3 tot 6 variabelen te representeren, de concurrenten samen te voegen tot één totaal-concurrent, de omgevingsfaktoren te bundelen in enkele macro-economische aggregaten benevens een trend, e.d. Zo mogelijk kan dit clusteringsproces worden gestuurd met behulp van een afzonderlijke faktoranalyse.

2 relativering, of wel het invoeren van verhoudingen tussen faktoren in plaats van de afzonderlijke faktoren zelf. Veel gebruikte transformaties in dit verband zijn de overgangen op verbruik- en inkomenscijfers per capita, op reële i.p.v. nominale inkomens en prijzen, op veranderingen van periode tot periode i.p.v. de absolute waarden der periode, en op aandelen c.q. verhoudingen tot gemiddelde marktwaarden voorzover het de marketing instrumenten betreft. (Vgl. ook hieronder.)

3 segmentering, m.a.w. een verdeling van een totaal in onderling onafhankelijke delen, die afzonderlijk worden geanalyseerd en vervolgens wederom gesommeerd. De totaalmarkt en de totale afzet kunnen worden opgevat als de som van een aantal deelmarkten en deelafzetten, waarvoor verschillende vraagfunkties kunnen gelden. Deze procedure biedt derhalve het voordeel van vereenvoudiging dus ook de mogelijkheid tot gelijktijdige verfijning. Bovendien kan op deze wijze mogelijkerwijs gemakkelijker worden rekening gehouden met uitgesproken kwalitatieve faktoren (zoals het assortiment en het distributiepatroon), omdat hiervoor middels de deelmarktanalyse speciaal wordt ,gecontroleerd". Vanzelfsprekend kan deze methode slechts worden toegepast als voldoende gegevens per deelmarkt ter beschikking staan, en deze inderdaad als onafhankelijk mogen worden beschouwd.

4 fasering, hetgeen een segmentering in onderling afhankelijke delen betekent. Gezocht wordt naar een stelsel van recursieve relaties, d.w.z. dat het resultaat van faze 1 wordt ingevoerd als verklarende variabele voor faze 2, etc. Het meest doelmatig is hier vermoedelijk een indeling in 3 fazen, te weten - vgl. ook het artikel van Verdoorn elders in dit nummer -:

a een omgevingsmodel, waarin het volgtijdelijk gedrag van de relevante omgevingsfaktoren wordt verklaard uit andere omgevingsfaktoren en/of een trend;

$b$ een marktmodel, waarin de totale effektieve vraag op de markt wordt gerelateerd aan de relevante omgevingsfaktoren (sub a) alsmede de gemiddelde marktofferte en de totale marktbewerking van alle concurrenten tezamen;

$c$ een marktaandeelmodel, waarin de eigen afzet van de onderneming in verband wordt gebracht met de totale effektieve vraag (sub b) en de marketing mix van de eigen onderneming en die der concurrenten.

Naarmate de kandidaatfaktoren in meerdere mate eenduidig kunnen worden toegerekend aan slechts één dezer fazen, zal deze fasering een reduktie tot praktisch $1 / 3$ van het oorspronkelijk aantal faktoren kunnen inhouden.

Indien deze vier reduktiemethoden simultaan worden gebruikt mag worden 
verwacht dat i.p.v. één zeer veel variabelen omvattende vergelijking nu een stelsel van deels afhankelijke, deels onafhankelijke vergelijkingen geschat moet worden, die elk evenwel slechts een fraktie van het oorspronkelijke aantal faktoren bevatten. Verfijning en vereenvoudiging gaan hierbij hand in hand, terwijl als extra voordeel een differentiatie van het marktgebeuren wordt gerealiseerd, welke rechtstreeks aansluit bij de evenzeer gewenste differentiatie van het commerciële beleid. Daar staat tegenover dat elke detaillering in het algemeen vraagt om meer detailinformatie. Het meest klemmend in deze is de eis om informatie omtrent het gedrag van concurrenten per deelmarkt op een continue basis ter beschikking te hebben.

\section{Specifikatie van het model}

Teneinde de vormgeving van het marketing model nader te illustreren zullen wij ons beperken tot de derde faze van de fasering sub 4, aangezien deze het meest direkt inhaakt op het commercieel beleid van de onderneming, en omdat een marktaandeelmodel een betrekkelijk recent fenomeen is in de theoretisch-economische en marktonderzoekliteratuur. Voor de modellen sub 4a) en 4b) zij o.m. verwezen naar het artikel van Verdoorn in ditzelfde nummer.

Als gezegd vormt de relatie tussen het eigen verkoopvolume enerzijds, en de totale effektieve vraag, alsmede de onderscheiden marketing mixes der concurrenten anderzijds, de centrale component van het marktaandeelmodel. De totale effektieve vraag op de markt wordt hierbij derhalve als een gegeven opgenomen, hoewel deze totale vraag mede beinvloed wordt door de commerciële programma's van de concurrenten. In theoretisch-economische termen beperken wij ons dus tot het zgn. substitutie-effekt der verkoopinstrumenten, terwijl het uitbreidingseffekt in het marktmodel ondergebracht wordt geacht. Passen wij nu de vereenvoudigingsprocedures $1 \mathrm{t} / \mathrm{m} 3$ successievelijk toe: clustering:

de marketing mix van elk der concurrenten wordt gerepresenteerd door een viertal variabelen, één voor elk der vier P's van de marketing mix; en tevens:

alle concurrenten worden samengevoegd tot één totaal-concurrent;

relativering: uit de twee variabelen eigen afzet en totale vraag op de markt wordt één nieuwe te verklaren variabele samengesteld, $\mathrm{nl}$. het mark taandeel (in volume gemeten), en tezelfdertijd worden analoge verhoudingscijfers geconstrueerd door de eigen instrumenten betreffende de marktofferte te relateren aan de gemiddelde offerte op de markt, en die betreffende de marktbewerking te relateren aan de totale marktbewerking van alle concurrenten tezamen - de eigen onderneming steeds inbegrepen -;

segmentering: de analyse wordt uitgevoerd voor één produkt en de daarbij behorende produktvariëteiten, en eveneens voor één distributiekanaal en de daarbij behorende distributiepunten; 
dan resulteert per saldo een quote-vergelijking, waarin het (relatieve) marktaandeel in het linkerlid, en een viertal vergelijkbare verhoudingscijfers voor elk der vier marketingdeelfunkties in het rechterlid van de vergelijking verschijnen. Duiden wij variabelen die betrekking hebben op de eigen onderneming aan met een index 1 , en variabelen betrekking hebbend op de totale markt met een index 0 , en geven wij het marktaandeel, de produktvariabele, de prijsvariabele, de distributievariabele en de verkoopbevorderingsvariabele respectievelijk weer door de symbolen $\mathrm{m}, \mathrm{q}$, p, d en $\mathrm{r}$, dan kan de vergelijking worden gesymboliseerd door:

$m_{1}=F \quad \frac{q_{1}}{q_{0}}, \frac{p_{1}}{p_{0}}, \frac{d_{1}}{d_{0}}, \frac{r_{1}}{r_{0}}$

Eenvoudig als deze funktie lijkt, zij is het nog allerminst. Het probleem is namelijk dat de vier marketingdeelfunkties dienen te worden gekwantificeerd in steeds één index, terwijl zij alle multidimensionaal zijn. De produktvariabele dient zowel het assortimentsaspekt als het kwaliteitsperceptie-aspekt te omvatten, de prijsvariabele zowel de prijsdifferentiatie (b.v. via rabatten) als de ,product line pricing”, de distributievariabele zowel de kwantiteit als de kwaliteit der verkooppunten, en de verkoopbevordering zowel de uitgaven aan reklame als die voor het vertegenwoordigersapparaat - om de belangrijkste elementen te noemen. De distributie- en produktvariabelen leveren door hun inherente kwalitatieve karakter daarbij de grootste vraagtekens op. Hiervoor lijkt als - veelal theoretische - oplossing een mogelijkheid te schuilen in indices, welke de gewogen dekking van de markt weergeven. De distributie dekking wordt dan verkregen door de totaalomzetten van de „eigen" verkooppunten in de betreffende produktenkategorie te relateren aan het markttotaal, terwijl de assortiments/kwaliteitsdekking wordt verkregen door een schatting van dat deel van de totale markt, dat met het eigen assortiment daadwerkelijk wordt bestreken. Daarnaast is het denkbaar dat middels een "rating" van alle produktvariëteiten en distributiepunten wordt gekomen tot een tweetal relatieve kwaliteitsvariabelen, één voor de produktvariabele en eveneens één voor de distributievariabele. Wat betreft de meer kwantitatieve prijs- en promotievariabelen, ligt het voor de hand in eerste instantie te werken met gemiddelde prijzen respectievelijk totale uitgaven. Ook in deze gevallen zal rekening moeten worden gehouden met wat onderzoektechnisch haalbaar is; het zal b.v. uitermate moeilijk vallen om de vertegenwoordigersinspanning van concurrenten tot guldens te herleiden, zo hierover al enige informatie ter beschikking staat. Wat betreft de reklame-uitgaven ligt de situatie ietwat eenvoudiger, voorzover het de reklame via de officiële media aangaat; deze wordt in ons land geregistreerd door o.m. het Centraal Bureau voor de Couranten Publiciteit (Bureau voor Budgetten Controle). Het spreekt overigens voor zich dat bedragen in guldens in dit opzicht weliswaar de meest voor de hand liggende, maar niet noodzakelijkerwijs beste maatstaven voor de getrooste inspanning opleveren.

Voorbijgaand aan deze kwantificeringsproblemen betreffende de marketing instrumenten, dient nu een specifikatie voor de tot dusver impliciet 
geformuleerde relatie te worden gegeven, welke plausibel is en tevens toetsbaar aan de hand van tijdreeksmateriaal. Aangezien de aangewezen techniek hier de multiple regressie is, verdient een specifikatie de voorkeur die gemakkelijk gelineariseerd kan worden. Waar anderzijds een volledig lineair model niet het meest plausibel is - vgl. de aanvang van dit artikel - komt men al snel tot de slotsom dat een multiplikatieve funktie met constante elasticiteiten een aanvaardbaar startpunt is. Hierbij valt op te merken dat deze constante coefficiënten niet vergelijkbaar zijn met de parameters uit de in de aanvang genoemde produktiefunktie: in linker- en rechterlid staan nu verhoudingsgetallen.

Waar de relatie het concurrentiepatroon in de tijd weerspiegelt, kan het wenselijk zijn om middels vertragingen het dynamisch karakter van het model te onderstrepen. De impliciete hypothese is dan, dat een verandering in de relatieve marketing mix in periode $t$ een marktaandeeleffekt teweeg brengt, dat slechts ten dele in de periode $\mathrm{t}$ zelf wordt gerealiseerd. Onder de veronderstelling dat de vertraagde effekten een dalende meetkundige reeks vormen kan dit fenomeen middels de bekende transformatie van KOYCK worden ingevoerd in het model door slechts één extra verklarende variabele op te nemen, te weten het marktaandeel in de direkt voorafgaande periode. De bijbehorende elasticiteit geeft dan impliciet de mate van vertraging aan.

De verhoudingsgetallen der instrumenten nu gemakshalve aanduidend met $q^{\prime}, p^{\prime}, d^{\prime}$ en $r^{\prime}$, resulteert de volgende specifikatie:

$\mathrm{m}_{1 \mathrm{t}}=\mathrm{a} \cdot \mathrm{q}_{1 \mathrm{t}}^{\mathrm{b}} \cdot \mathrm{p}_{1 \mathrm{t}}^{\mathrm{c}} \cdot \mathrm{d}_{1 \mathrm{t}}^{\mathrm{e}} \cdot \mathrm{r}_{1 \mathrm{t}}^{\prime \mathrm{f}} \cdot \mathrm{m}_{1, \mathrm{t}-1}^{\mathrm{g}}$

$\mathrm{b}, \mathrm{c}$, e en $\mathrm{f}$ zijn hier de constante quote-elasticiteiten, vergelijkbaar met de substitutie-elasticiteiten uit de theoretische economie, en wel voor de korte termijn (zelfde periode), terwijl de bijbehorende lange termijn-elasticiteiten worden verkregen door deze telkens te vermeniguuldigen met een faktor $1 /(1-\mathrm{g})$. De coëfficiënten $b, e, f$ en $g$ dienen positief te zijn, waarvan $g$ bovendien tussen 0 en 1 , terwijl de prijselasticiteit $c$ naar verwachting negatief zal zijn. De coëfficiënt a tenslotte, welke eventueel aprioristisch op $1 \mathrm{kan}$ worden gesteld, fungeert als een constante correctieterm voor systematische voordelen of nadelen van de eigen marktofferte c.q. marktbewerking in vergelijking met die van de concurrentie.

\section{Evaluatie van het model}

Vanzelfsprekend zijn varianten op bovengegeven specifikatie denkbaar, welke in de praktijk even goed of beter kunnen blijken te voldoen. Een bezwaar van de gegeven specifikatie is stellig, dat deze niet voldoet aan de additiviteitseis, d.w.z. dat, als dezelfde funktie (behoudens de coëfficiënt a) geldig wordt geacht voor alle concurrerende produkten, bij optelling over alle produkten in het rechterlid niet zonder meer de 1 resulteert, welke theoretisch wordt vereist. Modellen welke wel deze eigenschappen bezitten, laten zich echter aanzienlijk minder gemakkelijk empirisch verifiëren. 
Afgaande op enige recente publikaties kan het gegeven model de toets der kritiek zeer wel doorstaan. Afgezien van het klassieke onderzoek van BREMS naar de prijs- en kwaliteitssubstitutie tussen Ford en Chevrolet op de amerikaanse automobielenmarkt, dient in dit verband vooral te worden gewezen op de ,multi-instrument" studies van Telser, Weiss, Lambin, Gunter en Cowling.

Aangezien deze onderzoekingen zowel duurzame als niet-duurzame consumptiegoederen betreffen, geografisch zeer verschillende markten, en ook verschillende periodelengtes werden gebruikt, lijkt het model van voldoende bruikbaarheid. Zoals al deze onderzoekers benadrukken is het grootste probleem vrijwel steeds de verzameling van voldoende gedetailleerde en betrouwbare informatie, onmiddellijk gevolgd door de hierboven reeds aangestipte problemen rond de kwantificering der instrumenten. Wat betreft de distributie- en produktvariabelen is door geen dezer auteurs overigens een tenvolle bevredigende oplossing gevonden. De distributievariabele wordt veelal zonder meer geëcarteerd, terwijl assortiment en kwaliteit worden gerepresenteerd door dummyvariabelen (Weiss), door opinies van ,experts" (Lambin), door een gewogen aantal produktmodellen (Gunter), of in direkte samenhang met de prijsvariabele (Cowling). Waar dit type model momenteel door vele onderzoekers wordt bestudeerd, valt te verwachten, dat binnen niet te lange tijd aperte verbeteringen zullen worden aangebracht.

Het zou onjuist zijn, indien de toetsing van dit model alleen afhankelijk werd gesteld van de beschikbaarheid van tijdreeksen. Eerder moet worden gedacht aan een zinvolle kombinatie van alle marktinformatie welke beschikbaar is of kan worden gemaakt. Met name de mogelijkheid om door tests en experimenten deelfunkties van het model tastenderwijs te leren kennen, en de vergelijking middels doorsnedeanalyses van deelmarkt tot deelmarkt, kunnen hiertoe bijdragen.

Men kan zich afvragen in hoeverre een zo omstandige speurtocht naar een marketing model werkelijk noodzakelijk is voor een gezonde commerciële beleidsvoering. Het lijdt geen twijfel dat een doelmatig beleid zeer wel denkbaar is zonder theoretisch-economische abstrakties en wiskundige modellen. Wat telt is echter de ambitie om het risiko van de commerciële beslissingen zo klein mogelijk te doen zijn, om de best mogelijke doeleinden tot taakstellingen te verheffen, en om de beschikbare middelen zo doelmatig mogelijk in te zetten. Dat houdt tevens in een streven om gemaakte fouten te kunnen signaleren, lokaliseren en corrigeren, en om een antwoord paraat te hebben op eventualiteiten op de markt. Staat dit streven voorop, dan zal de speurtocht - hoe langdurig en aanvankelijk frustrerend ook - per saldo de moeite waard blijken, en gaandeweg als noodzaak worden onderkend. Het is hierbij van belang een onderscheid te maken tussen de diagnostische en de prognostische waarde van een dergelijk marketing model. Onder het eerste valt te verstaan het nut van het model bij de analyse van recente ontwikkelingen in markt en afzet en bij de beoordeling van de doelmatigheid van het gevoerde commerciële beleid, dit alles ex post dus. De prognostische waarde raakt het voorspellend vermogen van het model. Omdat het gebruik van een analy tisch model t.b.v. een voorspelling op korte of lange termijn de invoer van afzon- 
derlijke prognoses voor velerlei niet beheersbare variabelen kan vereisen, valt niet zonder meer aan te nemen, dat dergelijke voorwaardelijke voorspellingen een beter resultaat (kleinere gemiddelde voorspelfout) zullen opleveren dan meer mechanistische of naieve methoden, zoals een trendex trapolatie.

Niettemin geldt ook dan, dat het analytisch model een beter antwoord zal kunnen geven op momenten dat de „,normale” ontwikkeling wordt doorbroken op grond van strukturele wijzigingen in het marktgedrag. Het model kan stellig geen wapens bieden tegen calamiteiten in de omgeving, of tegen volkomen onverwachte (nieuwe) aktiviteiten van de concurrentie, maar deze komen gelukkig minder vaak voor. De diagnostische waarde van het model is in elk geval een niet aan te tasten voordeel.

\section{Konklusie}

Het construeren en verbeteren van markt- en marktaandeelmodellen vraagt om de continue aandacht van marktonderzoeker en commerciële leiding. Die aandacht is het best gegarandeerd als ook de marktinformatievoorziening op een systematische leest is geschoeid. Binnen het raamwerk van een ,marketing audit" in de zin van Verdoorn (zie Ferber \& Verdoorn) vinden modellen als de hierboven genoemde een vanzelfsprekende en centrale plaats. Het marktonderzoek kan hiermee, veel meer dan door pure informatieverzameling en marktbeschrijving, de fundamentele taak van beleidsondersteuning tot werkelijkheid brengen, en een onmisbare basis leveren voor planning en controle op het commerciële vlak.

\section{LITERATUUR}

J. Tinbergen. Economic Policy, Principles and Design. Amsterdam, 1956.

E. J. McCarthy. Basic Marketing. A Managerial Approach. Homewood Ill., 1960.

S. Banks. Experimentation in Marketing. New York, 1965.

C H. Sevin. Marketing Productivity Analysis. New York, 1965.

H. Brems. Product Equilibrium under Monopolistic Competition. Cambridge, 1951.

L. G. Telser. "Advertising and Cigarettes". Journal of Pol. Economy. Oct. 1962.

D. J. Weiss. „Determinants of Market Share”. Journal of Marketing Research. Aug. 1968.

J. J. Lambin. Modèles et Programmes de Marketing. Paris, 1970.

P. Gunter. „Marketing Modellen: een Verkenning”. Doctoraalskriptie NEH. 1971.

K. Cowling \& J. Cubbin. „Price, Quality and Advertising Competition”. Economica. Nov. 1971.

R. Ferber \& P. J. Verdoom. Research Methods in Economics and Business. New York, 1962. 